\title{
GROWTH RATE AND SALINITY PROFILE OF FIRST-YEAR SEA IGE IN THE HIGH ARGTIC
}

\author{
By M. Nakawo and N. K. SinHa \\ (Division of Building Research, National Research Council of Canada, Ottawa, \\ Ontario KIA oR6, Canada)
}

\begin{abstract}
This paper describes the growth of sea ice and the salinity profiles observed in Eclipse Sound near Pond Inlet, Baffin Island, Canada, during the winter of 1977-78. A numerical method of calculation has been developed to incorporate the variations in snow conditions and physical properties of ice and snow during the growth season. It is shown that the growth rate can be predicted reasonably well. It is also shown that the vertical salinity profile in the ice towards the end of the season, provides a record of previous climatological conditions. A dependence has been shown between the predicted growth rate and the measured salinity.

Résumé. Vitesse de croissance et profil de salinité de la glace de mer d'un an dans le Haut Arctique. Cet article décrit la croissance de la glace de mer et les profils de salinité observés à Eclipse Sound près de Pond Inlet, dans l'île de Baffin, Canada, pendant l'hiver 1977-78. On a mis au point une méthode numérique de calcul pour incorporer les variations dans les conditions de la neige et dans les propriétés physiques de la glace et de la neige pendant la saison d'accumulation. On montre que la vitesse de croissance peut être assez bien prévue. On montre, de plus, que les profils verticaux de salinité dans la glace, jusqu'à la fin de la saison, constituent un enregistrement des conditions climatologiques passées. On a montré qu'il y avait une liaison entre la vitesse de croissance prévue et la salinité mesurée.

Zusammenfassung. Wachstumsrate und Profil des Salzgehaltes einjährigen Meerieses in der hohen Arktis. Die Arbeit behandelt das Wachstum von Meereis und Profile des Salzgehaltes, die während des Winters $1977-78$ im Eclipse Sound nahe dem Pond Inlet auf Baffin Island, Kanada, beobachtet wurden. Es wurde eine numerische Berechnungsmethode entwickelt, welche die Änderungen der Schneeverhältnisse sowie physikalische Eigenschaften von Eis und Schnee während der Wachstumsperiode zu berücksichtigen gestattet. Die Wachstumsrate erweist sich als recht gut voraussagbar. Weiter zeigt sich, dass das Vertikalprofil des Salzgehaltes im Eis gegen das Ende der Periode hin eine Aufzeichnung früherer klimatischer Verhältnisse vermittelt. Zwischen der berechneten Wachstumsrate und dem gemessenen Salzgehalt wurde eine Abhängigkeit nachgewiesen.
\end{abstract}

\section{INTRODUGTION}

It is essential to know the quality of the ice, its thickness, and temperature for most engineering problems involving floating ice sheets. The quality of sea ice is dependent on salinity, air content, grain size and crystallographic orientation, and presence of cracks. Both thickness and quality are influenced by the past as well as the prevailing climatological conditions.

Many attempts have been made to predict the thickness of sea ice from climatological data (Zubov, I938; Tabata, I958; Billelo, I96r). No attention, however, has been paid to relating the ice quality to growth conditions in the field except for very thin ice $(<30 \mathrm{~cm}$ ) (Fukutomi and others, I95 I), although studies on this subject have been made in the laboratory (Weeks and Assur, 1963; Weeks and Lofgren, 1967; Cox and Weeks, 1975).

A substantial volume of data on the weather and snow and ice characteristics were collected in Eclipse Sound (lat. $72.7^{\circ}$ N., long. $78.0^{\circ}$ W.) near Pond Inlet, Baffin Island, Canada, during the winter season of $1977-78$. This paper describes analyses, using these field data, of the growth rate of first-year sea ice and the salinity profile in relation to the growth condition. The related subject of grain structure and air content will be presented at a later date.

\section{Observation methods}

An observation area of $100 \mathrm{~m} \times 100 \mathrm{~m}$ (designated Station No. $\mathrm{r}$ ), $0.5 \mathrm{~km}$ from the nearest shore, was selected on the sea ice at Eclipse Sound near Pond Inlet. The main camp and the laboratory (Arctic Research Establishment) were located on the land adjacent to the shore. 
Soon after the thickness of the ice sheet was enough to operate safely, the entire area was marked with flagpoles. The depth of water underneath the ice was about $150 \mathrm{~m}$.

A series of $7.5 \mathrm{~cm}$ diameter ice cores were recovered from the site at intervals of about a week beginning the first week of November 1977 and continuing to July 1978. The coring locations chosen were about $10 \mathrm{~m}$ apart in order to obtain undisturbed samples. Ice thickness and snow depth at the coring locations were recorded each time a core was recovered. Cores were taken to the main camp soon after the recovery from the ice sheet. Each core was then sectioned into segments of $2.5 \mathrm{~cm}$. The salinity of each segment of the cores was measured by a standard method. Salinity profiles through the thickness of the ice sheet were thereby obtained at regular intervals of time during the entire season.

A record of daily maximum and minimum air temperatures at the main camp was kept during the season. In addition, the temperature distribution through the thickness of the ice sheet was measured six times during the season at one location adjacent to the observation area. This was accomplished by means of a $2 \mathrm{~m}$ long probe with waterproof thermocouple junctions placed ro $\mathrm{cm}$ apart; the topmost sensor was placed in the ice, but only a few millimetres below the snow-ice interface.

Density of snow in the observation area was also measured at almost regular intervals of one week. Six samples (vertical cores) were obtained each time, which also provided additional data on snow depths.

\section{General observations}

There were, in all, five major cold and warm cycles during this season (Fig. I) before the final melting season started. The mean temperature fluctuated between -20 and $-40^{\circ} \mathrm{C}$ with an average of about $-30^{\circ} \mathrm{C}$ most of the time. It is important to note that the air temperature was below $-20^{\circ} \mathrm{C}$ during most of the ice-coring operations.

The thickness of the snow cover (Fig. 2) appeared to vary through the season. The trend was of the type

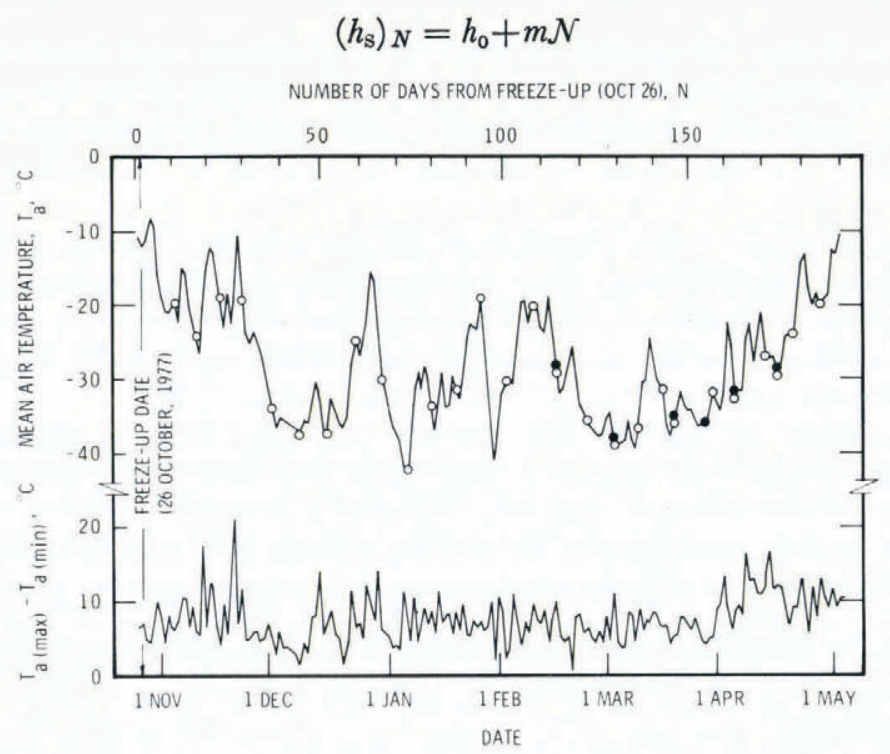

Fig. I. Variation of daily mean air temperature $\frac{1}{2}\left(T_{\mathrm{a}}(\max )+\mathcal{T}_{\mathrm{a}}(\min )\right)$ and corresponding difference between maximum and minimum temperatures during winter of 1977-78 at Pond Inlet. Open and solid circles indicate dates on which ice cores were taken and ice temperatures measured, respectively. 
where $\left(h_{\mathrm{s}}\right)_{N}$ is the thickness of snow on the $\mathcal{N}$ th day after freeze-up $(26$ October $1977 ; \mathcal{N}=\mathrm{I})$ and $h_{0}$ is the "initial thickness". An application of linear regression to the available data gave $m=0.039 \mathrm{~cm} / \mathrm{d}$ and $h_{0}=6.48 \mathrm{~cm}$ but the correlation coefficient was considered to be poor at 0.35 .

Because the depth of snow cover varied widely not only with time but also with location, it was decided to estimate an average snow thickness to represent the general snow condition in the test area. This representation is indicated by the solid line (I $1.4 \pm 4.2 \mathrm{~cm}$ ) in Figure 2.

As shown in Figure 2, the average seasonal snow density was $350 \pm 40 \mathrm{~kg} \mathrm{~m}^{-3}$, in good agreement with an earlier survey (Williams and Gold, 1958) of $35^{6} \pm 5^{2} \mathrm{~kg} \mathrm{~m}^{-3}$ at Resolute Bay not far from Pond Inlet.

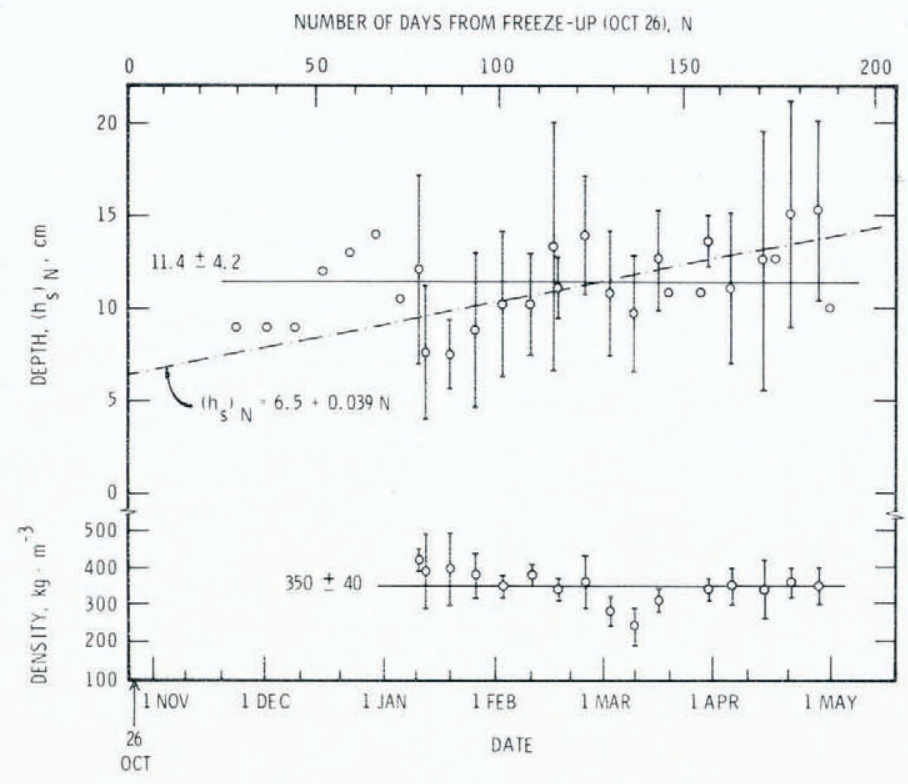

Fig. 2. Variation of snow depth and density during winter of 1977-78. Isolated circles for snow depth indicate single measurements, and circles with standard deviation bars describe the mean of six to eight measurements. Each data point for snow density indicates the mean of six measurements.

In general, an approximately linear temperature gradient in the ice was noted during the observation periods. Although the data on the temperature of the ice were far from exhaustive, the observations helped justify the formulation of the growth rate and its dependence on climatic conditions. This will be discussed in the next three sections.

Salinity was observed to be high at the top as well as at the bottom in almost all the ice cores. The average bulk salinity of the ice was high during the early growth period in November but was observed to decrease to a quasi-stable value of about $6 \%$ from December onwards (Fig. 6). A detailed discussion of the salinity profile in ice and its dependence on climatological conditions during the entire winter season will be presented in Sections 7 and 8.

\section{Growth condition}

Consider a growing ice sheet of thickness $h_{\mathrm{i}}$, with a snow cover of thickness $h_{\mathrm{s}}$, subjected to an ambient air temperature of $T_{\mathrm{a}}$. If the top-surface temperature of the snow cover is assumed to be given by $T_{\mathrm{a}}$ for simplicity and if $T_{\mathrm{b}}$ is assumed to be the snow-ice interface temperature, then under steady-state conditions 


$$
G_{\mathrm{i}}=\frac{T_{\mathrm{m}}-T_{\mathrm{b}}}{h_{\mathrm{i}}}
$$

and

$$
G_{\mathrm{s}}=\frac{T_{\mathrm{b}}-T_{\mathrm{a}}}{h_{\mathrm{s}}}
$$

where $G_{\mathrm{i}}$ and $G_{\mathrm{S}}$ are the temperature gradients in ice and snow respectively, and $T_{\mathrm{m}}$ is the melting point of ice. It is assumed implicitly that the physical properties of ice and snow are uniform through the respective depths.

If the increase in thickness of the ice sheet is $\Delta h_{\mathrm{i}}$ in a time period $\Delta t$, then the quantity of heat released during this freezing is $L \rho \Delta h_{\mathrm{i}}$ where $L$ is the latent heat of fusion and $\rho$ the density of ice. This amount of heat must flow through the ice and snow to the atmosphere, assuming there is no flow to the water underneath. Hence

$$
L \rho \Delta h_{\mathrm{i}}=k_{\mathrm{i}}\left(\frac{T_{\mathrm{m}}-T_{\mathrm{b}}}{h_{\mathrm{i}}}\right) \Delta t=k_{\mathrm{s}}\left(\frac{T_{\mathrm{b}}-T_{\mathrm{a}}}{h_{\mathrm{s}}}\right) \Delta t
$$

where $k_{\mathrm{i}}$ and $k_{\mathrm{s}}$ are the thermal conductivities of ice and snow respectively.

The second equality in Equation (4) gives

$$
T_{\mathrm{b}}=\frac{k_{\mathrm{i}} h_{\mathrm{s}} T_{\mathrm{m}}+k_{\mathrm{s}} h_{\mathrm{i}} T_{\mathrm{a}}}{k_{\mathrm{s}} h_{\mathrm{i}}+k_{\mathrm{i}} h_{\mathrm{s}}} .
$$

Equation (5) was also proposed by Zubov (1945) but the positive sign in the numerator was printed as negative in the original Russian version.

Substitution of $T_{\mathrm{b}}$ in Equations (2) and (3) gives

$$
G_{\mathrm{i}}=\frac{T_{\mathrm{m}}-T_{\mathrm{a}}}{h_{\mathrm{i}}+\left(k_{\mathrm{i}} / k_{\mathrm{s}}\right) h_{\mathrm{s}}}
$$

and

$$
G_{\mathrm{s}}=\frac{T_{\mathrm{m}}-T_{\mathrm{a}}}{\left(k_{\mathrm{s}} / k_{\mathrm{i}}\right) h_{\mathrm{i}}+h_{\mathrm{s}}} .
$$

Substitution of $T_{\mathrm{b}}$ of Equation (5) in Equation (4), gives

$$
\Delta h_{\mathrm{i}}=\frac{k_{\mathrm{i}} k_{\mathrm{s}}}{L_{\rho}} \frac{T_{\mathrm{m}}-T_{\mathrm{a}}}{k_{\mathrm{i}} h_{\mathrm{s}}+k_{\mathrm{s}} h_{\mathrm{i}}} \Delta t .
$$

If $\left(T_{\mathrm{a}}\right)_{N}$ is the mean air temperature of the $\mathcal{N}$ th day from the freeze-up date and $\Delta t$ is a period of time equivalent to one day $(\Delta t=\mathrm{I})$, then Equation (8) gives the daily growth rate as

$$
\left(\Delta h_{\mathrm{i}}\right)_{N}=\frac{k_{\mathrm{i}} k_{\mathrm{s}}}{L_{\rho}} \frac{\left\{T_{\mathrm{m}}-\left(T_{\mathrm{a}}\right)_{N}\right\}}{\left\{k_{\mathrm{i}}\left(h_{\mathrm{s}}\right)_{N}+k_{\mathrm{s}}\left(h_{\mathrm{i}}\right)_{N-\mathrm{I}}\right\}}
$$

where $\left(h_{\mathrm{S}}\right)_{N}$ is the average snow thickness on the day under consideration and $\left(h_{\mathrm{i}}\right)_{N-\mathrm{I}}$ is the ice thickness at the end of the previous day.

The total thickness of ice is then given by

$$
\sum_{\mathrm{I}}^{N}\left(\Delta h_{\mathrm{i}}\right)_{N}=\sum_{\mathrm{I}}^{\mathcal{N}} \frac{k_{\mathrm{i}} k_{\mathrm{s}}}{L \rho} \frac{\left\{T_{\mathrm{m}}-\left(\mathcal{T}_{\mathrm{a}}\right)_{N}\right\}}{\left\{k_{\mathrm{i}}\left(h_{\mathrm{s}}\right)_{N}+k_{\mathrm{s}}\left(h_{\mathrm{i}}\right)_{N-1}\right\}}
$$

or

$$
\sum_{\mathrm{I}}^{\mathcal{N}}\left\{T_{\mathrm{m}}-\left(T_{\mathrm{a}}\right)_{N}\right\}=\sum_{\mathrm{I}}^{\mathcal{N}} \frac{L \rho}{k_{\mathrm{i}} k_{\mathrm{s}}}\left\{k_{\mathrm{i}}\left(h_{\mathrm{s}}\right)_{N}+k_{\mathrm{s}}\left(h_{\mathrm{i}}\right)_{N-1}\right\}\left(\Delta h_{\mathrm{i}}\right)_{N} .
$$


Equation (II) thus relates the growth of ice in terms of accumulated degree-days of freezing. The integral form of Equation ( $\mathrm{I} I$ ) is given by

$$
\int_{0}^{t}\left(T_{\mathrm{m}}-T_{\mathrm{a}}\right) \mathrm{d} t=\int_{0}^{h_{\mathrm{1}}} \frac{L_{\rho}}{k_{\mathrm{i}} k_{\mathrm{s}}}\left(k_{\mathrm{i}} h_{\mathrm{s}}+k_{\mathrm{s}} h_{\mathrm{i}}\right) \mathrm{d} h_{\mathrm{i}} .
$$

For conditions of constant snow thickness, Equation (12) reduces to

$$
\int_{0}^{t}\left(T_{\mathrm{m}}-T_{\mathrm{a}}\right) \mathrm{d} t=\frac{L \rho}{2 k_{\mathrm{i}}} h_{\mathrm{i}}{ }^{2}+\frac{L \rho h_{\mathrm{s}}}{k_{\mathrm{s}}} h_{\mathrm{i}},
$$

which in the absence of any snow cover reduces further to

$$
\int_{0}^{t}\left(T_{\mathrm{m}}-T_{\mathrm{a}}\right) \mathrm{d} t=\frac{L \rho}{2 k_{\mathrm{i}}} h_{\mathrm{i}^{2}} .
$$

Equation (13) bears close resemblance to Zubov's (1938) empirical formulation

$$
\sum\left(T_{\mathrm{m}}-T_{\mathrm{a}}\right)=A h_{\mathrm{i}}^{2}+B h_{\mathrm{i}} \text {. }
$$

Equation (14), on the other hand, is similar to the widely used empirical equations of the form

$$
\sum\left(T_{\mathrm{m}}-T_{\mathrm{a}}\right)=C h_{\mathrm{i}}{ }^{D},
$$

applied successfully to field data by several investigators (for example Tabata, 1958; Billelo, I96I). The left-hand sides in Equations (I5) and (I6) usually represent the accumulated degree-days of freezing; $A, B, C$, and $D$ are constants; and $D$ is usually found to be close to 2 .

As early as 1891 , Stefan gave a rigorous mathematical treatment to this problem while discussing the thickness of the polar ice sheet (Carslaw and Jaeger, 1959). His solution reduces to Equation (14) for steady-state conditions. Zubov (1945) used Equation (12) in discussing the possible effect of a snow cover on the growth of ice formed from fresh-water ice. Anderson (1961) used a relation of the form similar to Equation (I2) to formulate the growth of ice, but ultimately resorted to an "eye fit" to the field data. Simpson (1958) used the basic Equation (12) in predicting the growth of sea ice in the Arctic but did not provide actual ice thickness data. Kolesnikov (1958) formulated the growth equation of ice on a much broader basis than the simple form of Equation (12), but his formulations have not, to the authors' knowledge, been tested using field data.

The effect of incoming solar radiation is neglected in deriving Equations (I2)-(I4). It was considered, however, that the treatment should be applicable to the present study because of the near absence of sunlight in the High Arctic during most of the growing season and the low elevation of the sun during the rest of the growth period.

\section{Temperature Distribution in ICE AND snow}

Both the numerical (Equations (IO) and (II)) and the integral (Equation (I2)) forms of the growth of ice are based on the assumption that the temperature gradients in both the snow cover and the ice are linear and given by Equations (6) and (7), respectively. These assumptions were tested using the values for the properties of snow and ice given in Table I and assuming that $T_{\mathrm{a}}$ was equal to the mean air temperature for the days under consideration. Computed temperatures of the snow-ice interface and the temperature distributions in the snow and ice were then compared with the measured data in Figure 3 for two sets of measurements. The estimated and the measured temperature gradients in the ice, for the six measurements mentioned earlier, are compared in Figure 4. It is significant that four of the six comparisons are very good. The simple model of growth conditions simulated reasonably well the natural conditions at this site in the High Arctic. 
Table I. Physical properties of snow and ice

Average salinity of water in the test area in Eclipse Sound $=32 \%$

$T_{\mathrm{m}}=-1.8^{\circ} \mathrm{C}$ for sea-water with salinity of $32 \%$. (See also the measured water temperature in Fig. 3 .)

$\rho=900 \pm 10 \mathrm{~kg} \mathrm{~m}^{-3}$ (density of sea ice at Eclipse Sound, measured at DBR/NRC).

$L=70 \mathrm{cal} \mathrm{g}^{-1}\left(293 \mathrm{~J} \mathrm{~g}^{-1}\right)$ (Anderson, 1960; Schwerdtfeger, 1963; Ono, 1968).

$k_{1}=5 \times \mathrm{ro}^{-3} \mathrm{cal} \mathrm{cm}^{-1} \mathrm{~s}^{-1} \mathrm{deg}^{-1}\left(2.1 \mathrm{~W} \mathrm{~m}^{-1} \mathrm{deg}^{-1}\right)$ for sea ice of about $6 \%$ salinity (Schwerdtfeger, 1963; Ono, 1968).

$h_{\mathrm{s}}=11.4 \pm 4.2 \mathrm{~cm}$ (average of all the snow-depth data collected at the test area over the entire growth season of $1977-78$; Fig. 2 ).

Snow density $=350 \pm 40 \mathrm{~kg} \mathrm{~m}^{-3}$ (measured for the area; Fig. 2)

$k_{\mathrm{s}}=6 \times \mathrm{IO}^{-4} \mathrm{cal} \mathrm{cm}^{-1} \mathrm{~s}^{-1} \mathrm{deg}^{-1}\left(0.25 \mathrm{~W} \mathrm{~m}^{-1} \mathrm{deg}^{-1}\right)$ for snow density of $35 \mathrm{okg} \mathrm{m}^{-3}$ at -20 to $-30^{\circ} \mathrm{C}$ (Pitman and Zuckerman, 1968; Mellor, 1977).

The plot for 16 February shown in Figure 3 indicates that some consideration should be given to the thermal history previous to the days of measurement because the warm week prior to 16 February (see Fig. I) led to a lower-than-predicted temperature gradient in the ice. In addition, a complete analysis must take into consideration the effects of wind and cloud cover, if any, on the heat-transfer conditions at the exposed snow surface, the disturbance that might be introduced in the temperature distribution by the presence of the probe itself, and the uncertainty of the thermal conductivities of snow and of the highly saline upper and bottom layers of the ice itself, etc. These refinements are outside the scope of this paper.

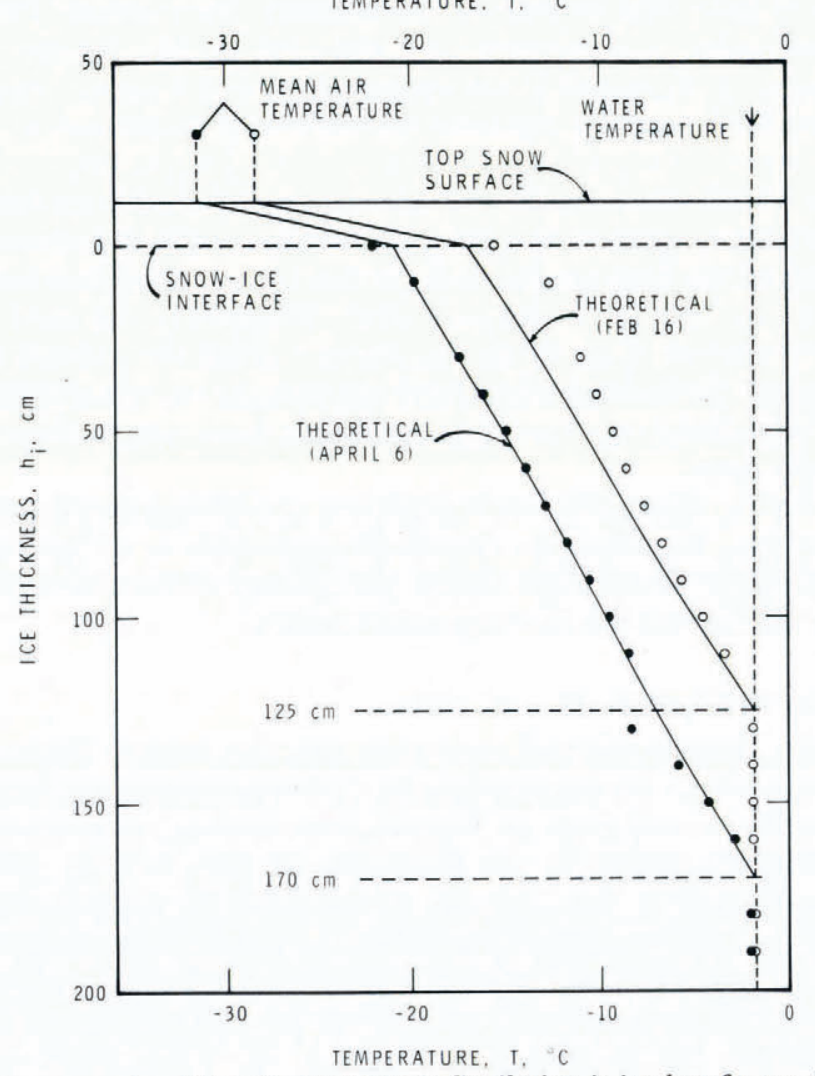

Fig. 3. Comparison between measured and theoretical temperature distributions in ice sheet for two days in 1978 . Theoretical calculations are based on mean air temperatures for days shown, water temperature of $-1.8^{\circ} \mathrm{C}$, snow depth of $11.4 \mathrm{~cm}$ and ice thickness estimated from temperature distributions. 


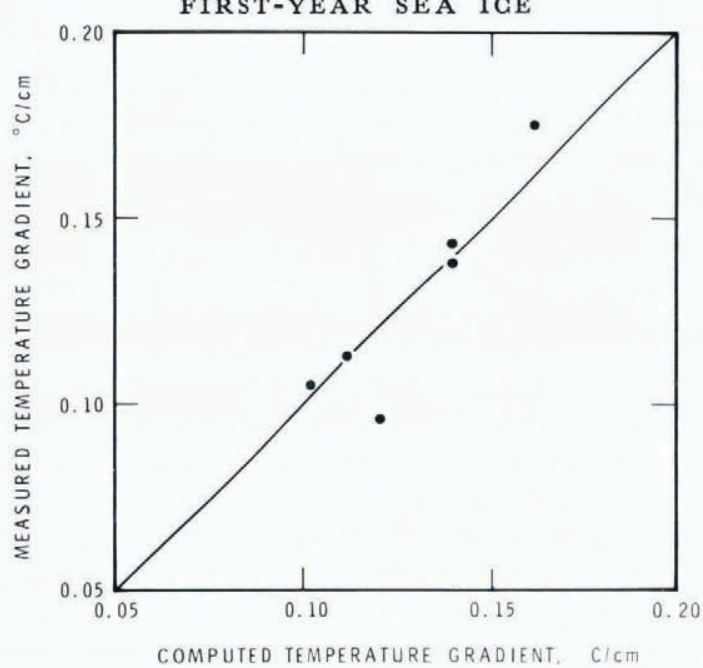

Fig. 4. Comparison between calculated and measured temperature gradients in an ice sheet for six measurements carried out during February-April $197^{8}$, in Eclipse Sound.

\section{Growth of SEA iae in Eclipse Sound}

Figure 5 illustrates the growth of ice in the test area in Eclipse Sound as a function of accumulated degree-days of freezing. Dates are also given to indicate the time of the season. The calculated results, indicated by the solid and the two broken lines, are based on Equation (I I) with constant snow thickness (I I. $4 \pm 4.2 \mathrm{~cm}$ ) and the physical properties of ice and snow given in Table I. Calculations using Equation (13) also gave the same results.

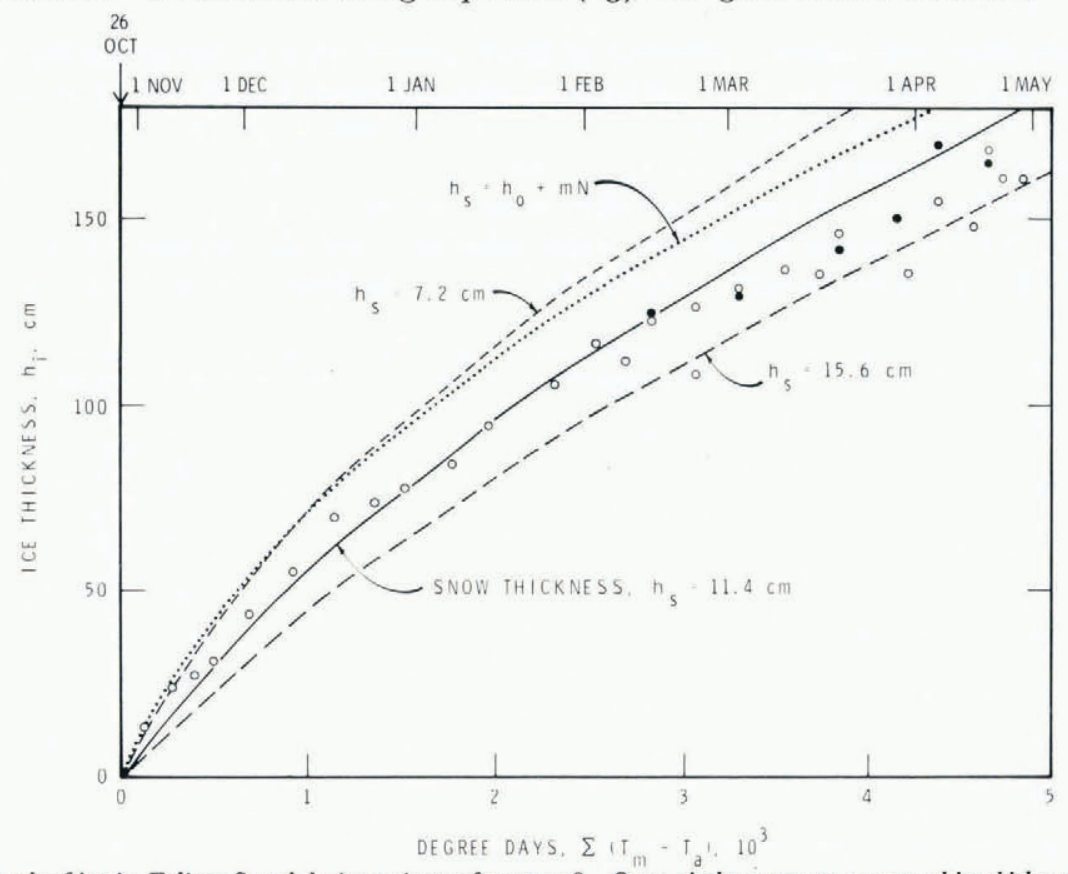

Fig. 5. Growth of ice in Eclipse Sound during winter of 1977-78. Open circles represent measured ice thicknesses. Solid circles give thicknesses estimated from measured temperature distributions. Solid and broken lines are calculations (Equation (II)) for snow thicknesses of $I I .4 \pm 4.2 \mathrm{~cm}$. Dotted line is based on Equation (I7) for variable snow thicknesses. 
Although the deviation was within the predicted scatter, the measured growth curve appears to deviate slightly from the mean calculated result. It would appear that the gradual thickening of the snow cover with time should be taken into consideration. Substitution of $\left(h_{\mathrm{S}}\right)_{N}$ of Equation ( $\mathrm{I}$ ) in Equation (10) gives

$$
\sum_{I}^{\mathcal{N}}\left(\Delta h_{\mathrm{i}}\right)_{N}=\sum_{\mathrm{I}}^{\mathcal{N}} \frac{k_{\mathrm{i}} k_{\mathrm{s}}}{L_{\rho}} \frac{\left\{\mathcal{T}_{\mathrm{m}}-\left(\mathcal{T}_{\mathrm{a}}\right)_{N}\right\}}{\left\{k_{\mathrm{i}}\left(h_{\mathrm{o}}+m \mathcal{N}\right)+k_{\mathrm{s}}\left(h_{\mathrm{i}}\right)_{N-1}\right\}} .
$$

Calculations based on Equation ( 17 ) and Table I, shown by the dotted line in Figure 5, overestimated the thickness in general.

The failure of an apparently more rigorous method of calculation to give better agreement with the observed growth could be due to Equation (I) not representing the snow conditions during the early growth period. Moreover, it is highly possible that the density of snow and hence its thermal conductivity $\left(k_{\mathrm{s}}\right)$ were less during the early growth period than the average value used in the calculations. The results in Fukutomi and others (1950) and Tabata (1958) indicate that, early in the season, $L \rho / k_{\mathrm{i}}$ could be larger than the value used because of the high salinity of freshly frozen ice. These factors would lead to a lower growth rate and smaller ice thickness. Equation ( I 7 ) must take into account the time dependency of $L, \rho, k_{\mathrm{i}}$, and $k_{\mathrm{s}}$, and requires a better measurement of the early snow conditions in order to be realistic. However, none of the above physical properties of saline ice and snow are known with any degree of confidence in the period when the ice is quite thin.

The overall success of the calculations with constant snow thickness lies in the possibility that the assumed thicker snow somehow compensates for the effect of low $k_{1}$ and low $k_{\mathrm{s}}$ with thinner snow cover during the early stage. The late-season deviation could partly be due to the increasing availability of solar radiation.

\section{Salinity of iae}

Because ice cores were taken at intervals of about a week through the entire season from a selected area, it was anticipated that the salinity measurements would show the evolution of the salinity distribution corresponding to the growth conditions experienced in the test area. The evolution of the salinity profile during the period from early November 1977 to late April 1978 is shown in Figure 6. A two-week interval was chosen for clarity.

Almost all the measurements showed high salinities near the bottom of the cores, an indication of the high brine content of freshly frozen ice. Although the air temperatures were

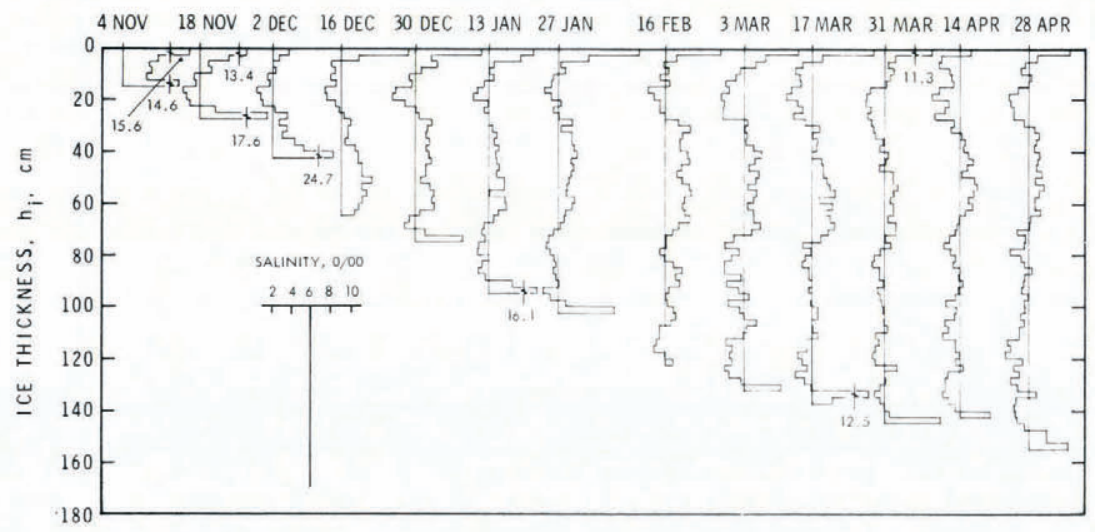

Fig. 6. Salinity profile in ice of Eclipse Sound at intervals of two weeks during winter of 1977-78. Scale for salinity is shown in insert. Vertical solid lines represent a value of $6 \%$ and are given as a reference. 
below $-20^{\circ} \mathrm{C}$ during recovery of most of the cores (Fig. I), there is doubt whether the measured salinities truly represented the in-situ salinities of the bottom layers because of the possibility of drainage during the removal of the cores from the ice sheet. In spite of this uncertainty, Figure 6 confirms earlier observations (Malmgren, 1927; Weeks and Lee, 1958) that the salinity of freshly frozen sea ice decreases rapidly during the period after initial freezing. This observation is illustrated more clearly in Figure 7 for a section between 40 to $42.5 \mathrm{~cm}$ below the top ice surface. It can be seen that the salinity of $25 \%$ measured on 2 December dropped to $8.5 \%$ on 9 December. It seems that the major reduction in the brine content occurs within a week after the formation.

Figure 7 also indicates that, as the freezing front moves downwards, the salinity at a given depth attains a "quasi-stable" value. Following the initial rapid desalination, the salinity of each level is relatively constant but has a tendency to decrease slowly during the rest of the season. This stable salinity at the level of 40 to $42.5 \mathrm{~cm}$ is indicated in Figure 7 where the dashed line is the average $S$ of all the data, excluding the initial high values. The attainment

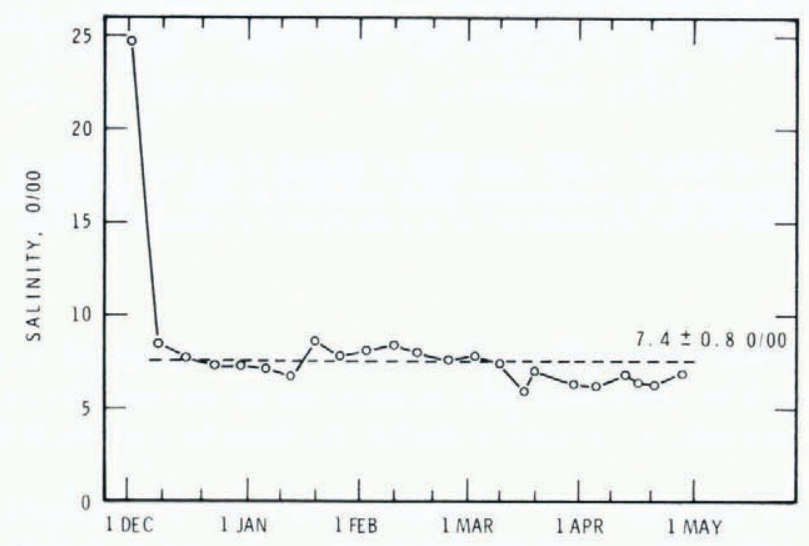

Fig. 7. Variation of salinity with time for $2.5 \mathrm{~cm}$ sections of ice at a depth between 40 and $42.5 \mathrm{~cm}$. Broken line indicates "stable" salinity or average of all the salinities except the initial high value at this ievel.

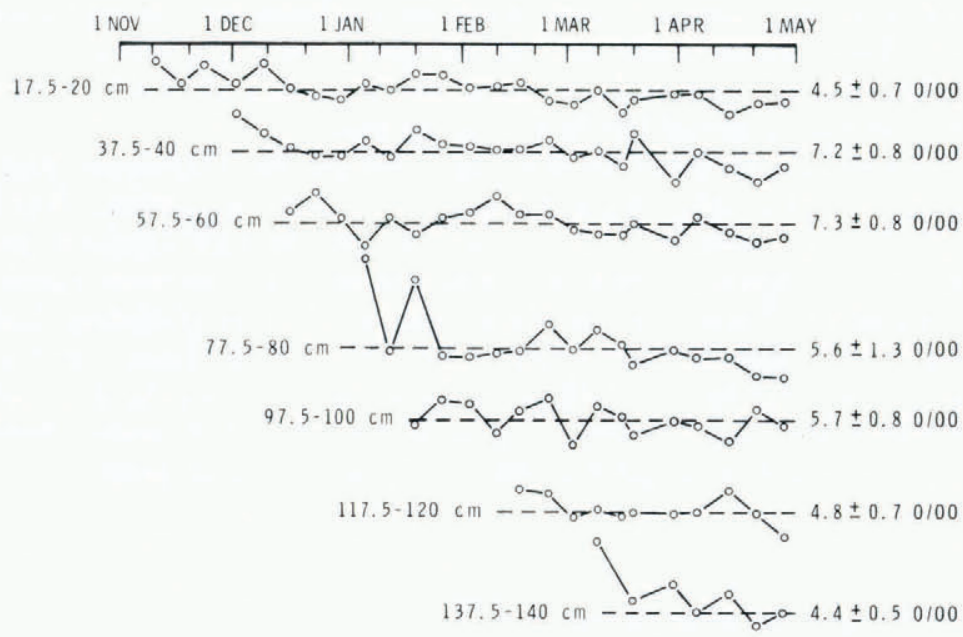

Fig. 8. Attainment and retention of "stable" brine content at a given depth, during winter of $1977-78$, for various depths at intervals of $20 \mathrm{~cm}$ as shown. 


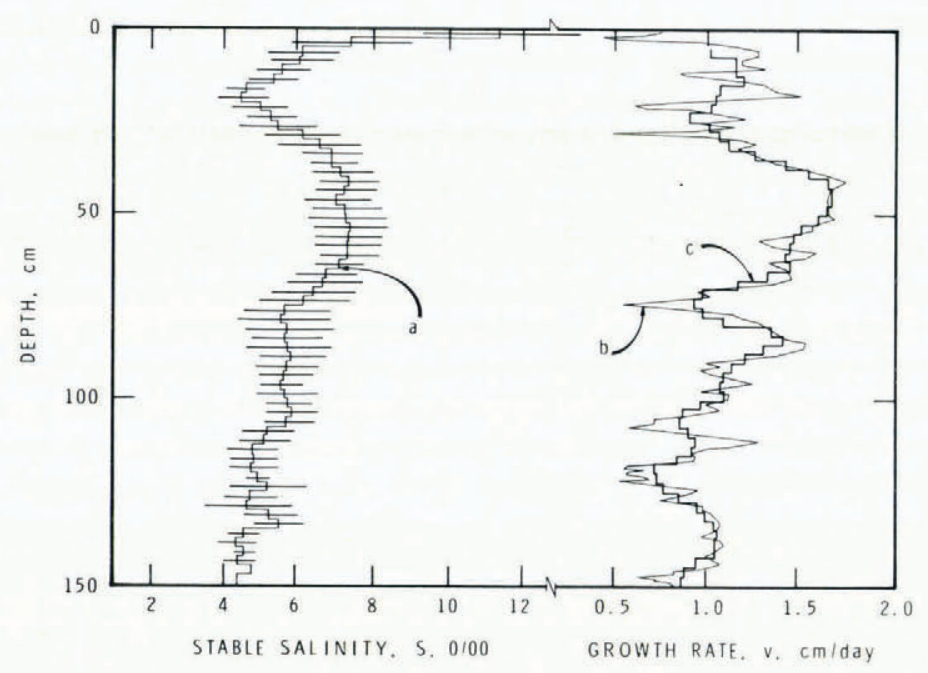

Fig. 9. Curve a shows variation of "stable" salinity with depth at intervals of $2.5 \mathrm{~cm}$. Horizontal bars represent standard deviations. Curve $b$ gives dependence of growth rate on depth, calculated on basis of air temperatures. Curve $c$ represents running mean of calculated growth rate for an interval of $\pm 5 \mathrm{~cm}$ for every $2.5 \mathrm{~cm}$ segment of ice.

and retention of a stable brine content at a given depth during the rest of the winter is demonstrated further in Figure 8 for various depths at intervals of $20 \mathrm{~cm}$. The value of this stable salinity was observed, however, to depend on depth, as shown by curve a in Figure 9 for every $2.5 \mathrm{~cm}$ segment.

At a given depth, the variation in stable salinity during the season was found to be about $\mathrm{I} \%$. Some of the apparent scatter in the measurements could be due to the neglect of the slow desalination. Another source of scatter is the possibility that a layer at a given depth could have formed at different times in the different cores, as indicated by the variations in ice thickness shown in Figure 5. The variation in the ice thickness was most probably caused by the fluctuations in the thickness of the snow cover during the early season.

In addition, the breaks in the cores, and the necessity of cutting them into smaller segments, would introduce uncertainty about the level of a segment.

The near constancy of salinity of ice was also observed by Malmgren (1927) during an expedition to the Polar Sea and by Bennington (1967) at Barrow, Alaska. It is interesting to note that their observations were made at locations geographically similar to the present site with comparable climatological conditions. The continuous, relatively rapid desalination noticed by Weeks and Lee (1958) even in December/January at Hopedale, Labrador, must have been caused by the reported warmer mean temperatures of about $-10^{\circ} \mathrm{C}$, which could have influenced not only the in-situ desalination processes but also the drainage during the recovery of specimens from the ice sheet. Desalination with increasing rapidity was also observed in the present study at Pond Inlet but not until May and June.

\section{SALINITY PROFILE AND GROWTH HISTORY}

Figure ro presents a composite diagram of the "stable" salinity profile, the variation of daily mean temperature with time, and the growth history. The broken line represents an 


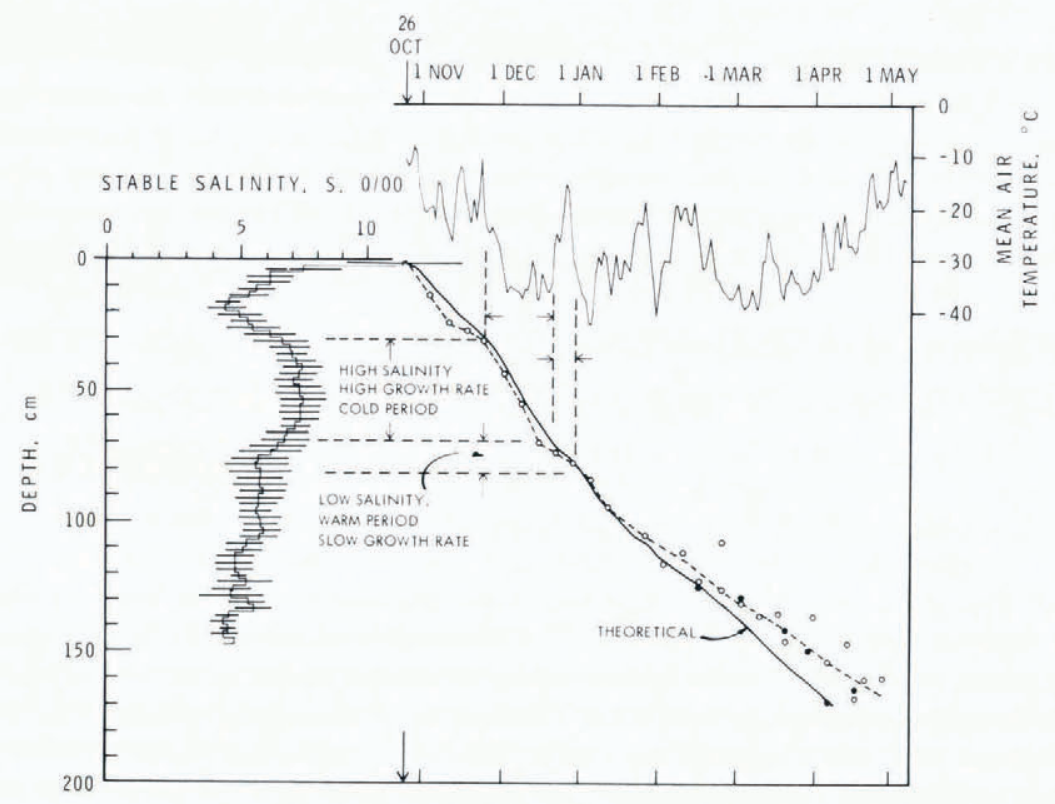

Fig. Io. Composite diagram of "stable" salinity profile, variation of daily mean air temperature with time during winter of $1977-78$, and growth history of the ice. Open circles are measured ice thicknesses. Solid circles give thicknesses estimated from measured temperature distributions. Growth curve (broken line) is an "eye-fit"; solid curve is based on theory. High salinity is related to high growth that corresponds to colder periods. Warmer days slowed the growth of ice, resulting in lower salinity.

"eye fit" to the measured thickness, and the solid line gives the calculated growth curve shown by the solid line in Figure 5. Because most of the measured points were obtained from the length of the ice cores used for determining the salinity profile, the history of the salinity profile can be traced indirectly through the observed growth curve as discussed in the following.

It can be seen in Figure ro that both the observed and the calculated growth histrory show dependence of growth rate on mean air temperature. Warmer periods, for example at the end of both November and December, resulted in slower growth rates, whereas colder periods in December and mid-January enhanced the rate of growth. It is interesting to note that the stable salinity profile also exhibits, like the growth rate, a record of the major weather changes that occurred during the growth period. The low salinity of $4 \%$ at a depth of 10 to $30 \mathrm{~cm}$ seems to be related to the slow growth rate corresponding to the warm period in November. High salinity of $7.5 \%$ recorded at a depth of 40 to $60 \mathrm{~cm}$ correlates well with the higher growth rate initiated by the cold period in December. Further correspondence can also be seen, although the variation of the stable salinity decreased with depth because of the decreased effect of weather changes on the growth rate with increased thickness. Moreover, the averaging method used in estimating the stable salinity profile also effectively reduced the value of the salinity gradient at greater depths. Individual salinity profiles, shown in Figure 6, indicated these variations more clearly. For example, the relatively lower salinities at a depth of about 70 to $80 \mathrm{~cm}$ and again at 1 Io to $120 \mathrm{~cm}$ (i.e. the salinity profile of 17 March or ${ }_{14}$ April, Fig. 6) correlate well with the warmer periods at the end of December and middle of February respectively, whereas the comparatively higher salinity developed at 80 to $100 \mathrm{~cm}$ relates well with the colder period in the first three weeks of January. 


\section{Growth RAte AND SAlinity}

Quantitative dependence of stable salinity on growth rate can be established by relating the stable salinity of a section of ice at a given depth with its corresponding growth rate. This can be achieved in two ways under the present situation-either using the observed growth history or making use of the calculated rate of growth. It was decided to begin with the second approach. Comparison with the estimated growth rate determined from the thickness measurements will be made later.

Curve b in Figure 9 gives the growth rate, $\left(\Delta h_{\mathrm{i}}\right)_{N}$ (Equation (9)) on the $\mathcal{N}$ th day as a function of the average thickness of ice for the same day $\left\{\sum_{1}^{N-1}\left(\Delta h_{\mathrm{i}}\right)_{N}+\frac{1}{2}\left(\Delta h_{\mathrm{i}}\right)_{N}\right\}$ estimated from Equation ( 10 ). Similarities between curves $\mathrm{a}$ and $\mathrm{b}$ are quite pronounced and consistent with the discussions in the previous section.

The stable salinity profile is considered reliable only down to a depth of about $125 \mathrm{~cm}$ because of the decreasing number of samples for calculating the average, as can be seen in Figure 8. The theoretical and the observed growth curve agreed with each other to within $\pm 5 \mathrm{~cm}$ down to about that depth (Fig. Io). For these reasons, as well as for compatibility with the stable salinity profile and its associated scatter discussed in Section 7, it was decided to calculate a running mean of growth rate for an interval of $\pm 5 \mathrm{~cm}$ for every $2.5 \mathrm{~cm}$ segment of ice. The results are shown by the stepped curve $c$ in Figure 9. It is smoother than curve b and probably more realistic because the thermal inertia of the snow-ice system would dampen the variations in the temperature and hence the growth rates, which are calculated on the basis of daily air temperatures.

The two curves, a and c, in Figure 9 show an average bulk salinity of about $6 \%$ corresponding to a seasonal average growth rate of about $1.2 \mathrm{~cm}$ per day. This conforms well with the generally reported observations on salinity and growth rate for first-year sea ice in the Canadian High Arctic.

The salinity $S$ of each $2.5 \mathrm{~cm}$ segment of curve a is plotted in Figure I I against the corresponding growth rate $v$ of curve b of Figure 9 (for depths between 25 and $125 \mathrm{~cm}$ ). The $25 \mathrm{~cm}$

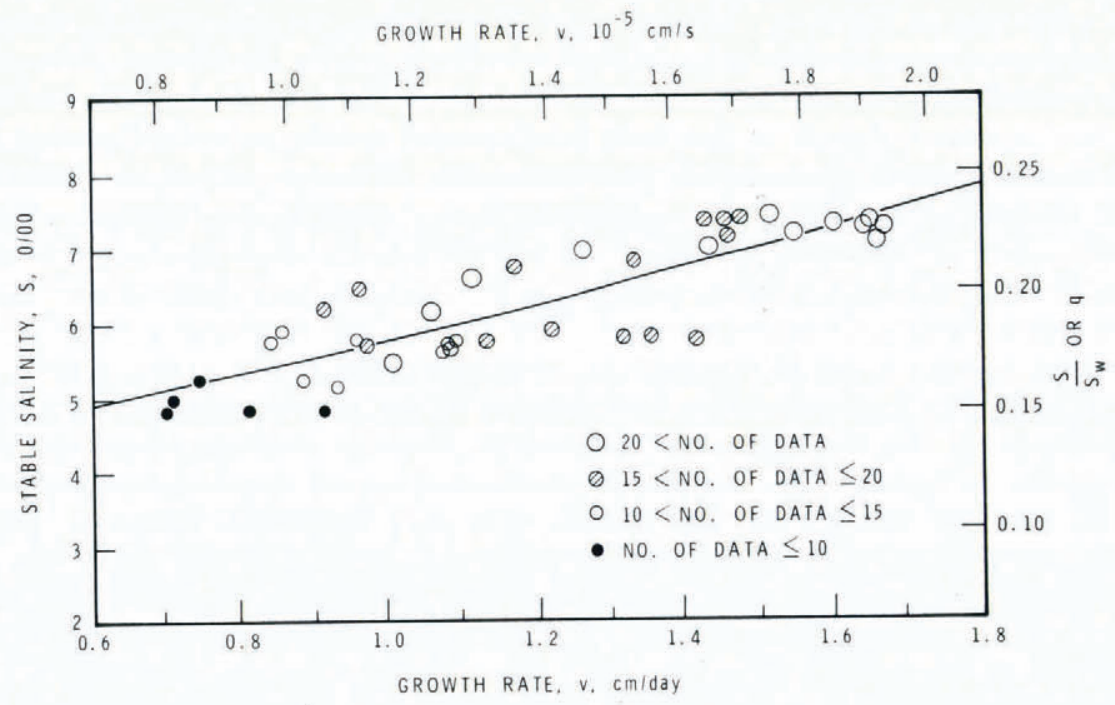

Fig. II. Plot of "stable" salinity $S$ of each $2.5 \mathrm{~cm}$ segment of curve a versus corresponding growth rate $v$ of curve $b$ of Figure 9 for columnar-grained ice at depths between 25 and $125 \mathrm{~cm}$. Number of segment salinities available for determining each $S$ value is shown. Solid line represents Equation $(18)$ for $\delta / D=4.2 \times 10^{4} \mathrm{~s} / \mathrm{cm}$ and $q_{0}=0.12$. 
limit was imposed to avoid the transition zone because continuous columnar-grained ice was observed below this depth.

By adopting the theoretical considerations of Burton and others (r953), Weeks and Lofgren (1967) proposed the following relation for their $\mathrm{NaCl}$ ice made in the laboratory:

$$
q=\frac{q_{0}}{q_{0}+\left(\mathrm{r}-q_{0}\right) \exp (-\delta v / D)}
$$

where $q$ is the effective solute distribution coefficient defined as the solute concentration in the solid divided by the solute concentration in the solution, $q_{0}$ is the effective value of $q$ for the extremely low growth rate $v, D$ is the diffusion coefficient of the solute in the solution, and $\delta$ is the thickness of the diffusion-limited boundary layer.

Rearrangement of Equation (18) gives

$$
\ln \left(\frac{\mathrm{I}}{q}-\mathrm{I}\right)=\ln \left(\frac{\mathrm{I}}{q_{0}}-\mathrm{I}\right)-\frac{\delta}{D} v .
$$

In the present case $q=S / S_{\mathrm{w}}$ and $q_{0}=S_{\mathrm{o}} / S_{\mathrm{w}}$ where $S_{\mathrm{w}}$ is the salinity of water and $S_{0}$ is the effective value of salinity for an extremely low growth rate. Substitution of these in Equation (19) gives

$$
\ln \left(\frac{S_{\mathrm{w}}}{S}-\mathrm{I}\right)=\ln \left(\frac{S_{\mathrm{w}}}{S_{0}}-\mathrm{I}\right)-\frac{\delta}{D} v .
$$

Results presented in Figure I I are replotted in Figure I 2 to examine whether $\ln \left(S_{\mathrm{W}} / S-\right.$ I $)$ is linearly dependent on $v$ as Equation (20) suggests. The trend is obvious though the scatter is large. A least-square fit of all the data gave $\delta / D=4.2 \times 10^{4} \mathrm{~s} / \mathrm{cm}$ and $S_{0} / S_{\mathrm{w}}$ or $q_{0}=0.12$ $\left(S_{0}=3.8 \%\right.$ for $S_{\mathrm{w}}=32 \%$ ) with a correlation coefficient of o.84. The range of growth rate was not large and therefore it would not be wise to extrapolate this analysis. No special significance can be given to the values of $q_{0}$ or $\delta / D$.

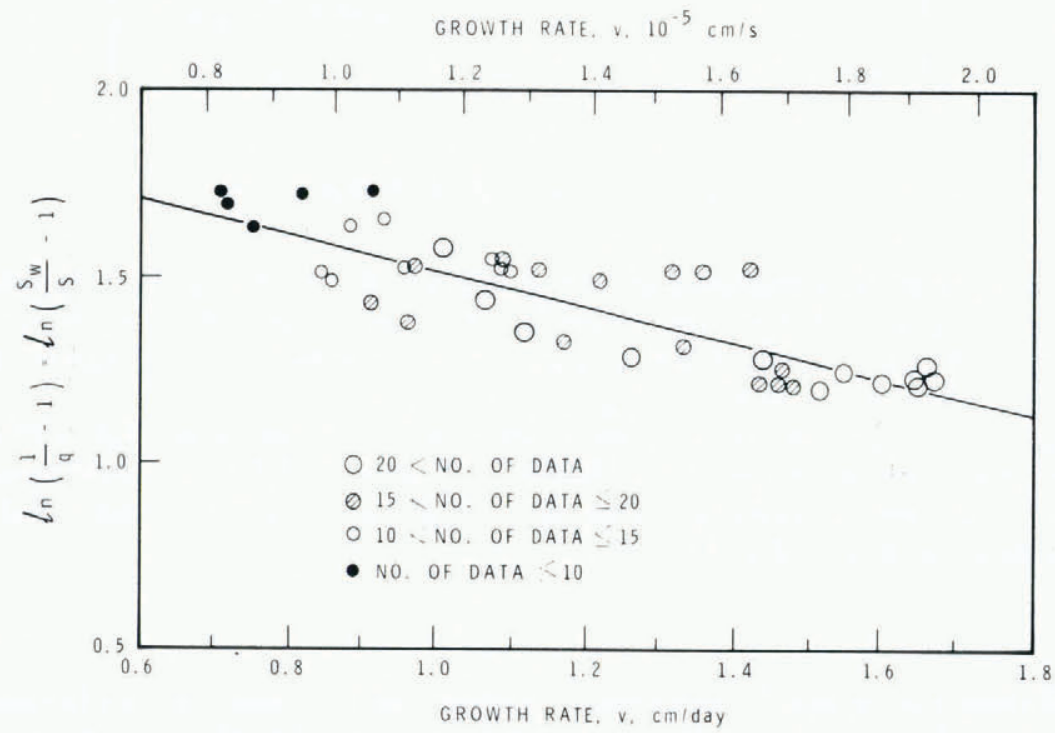

Fig. 12. Plot of $\ln (I / q-I)$ or $\ln \left(S_{\mathrm{w}} / S-I\right)$ versus growth rate for columnar-grained ice observed for depths between 25 and $125 \mathrm{~cm}$. Number of segment salinities available for determining each $S$ value is shown. Solid line represents the least-square fit of Equation (20) to all the data, giving $\delta / D=4.2 \times 10^{4} \mathrm{~s} / \mathrm{cm}$ and $q_{0}$ or $S_{0} / S_{\mathrm{w}}=0.12$. 
Columnar-grained ice, consisting of long columns with their [ooor] axes perpendicular to the growth direction, was observed to form below a depth of about $25 \mathrm{~cm}$. The above analysis, made for ice below $25 \mathrm{~cm}$, is therefore considered valid for conditions leading to the formation of this type of ice. Vertical variation in the texture and the fabric of columnargrained ice, and its dependence on growth conditions, will be discussed in a later publication.

Between about 2 and $25 \mathrm{~cm}$, the ice consisted of discontinuous columnar grains; the length of the columns was less than about $\mathrm{I} \mathrm{cm}$. Fine-grained granular ice was observed at the top $2 \mathrm{~cm}$ of the ice sheet. The results for the ice above $25 \mathrm{~cm}$ are shown in Figure 13 for comparison. These were, as can be seen from Figure 9, for depths below $5 \mathrm{~cm}$ because of the limitations imposed by the method of calculating the mean growth rate. No significant differences can be seen in these results from those for continuous columnar-grained ice. Figure 9 shows, however, a relatively high salinity of $\mathrm{I}$ I. $4 \pm 2.2 \%$ corresponding to a growth rate of about $0.6 \mathrm{~cm} /$ day for the topmost $2.5 \mathrm{~cm}$ section of the ice sheet. Although the magnitude of the growth rate is doubtful, the example indicates the possibility that fine-grained granular ice retains more brine than columnar-grained ice for a given growth history. This perhaps explains the generally observed high salinity at the top of first-year sea ice.

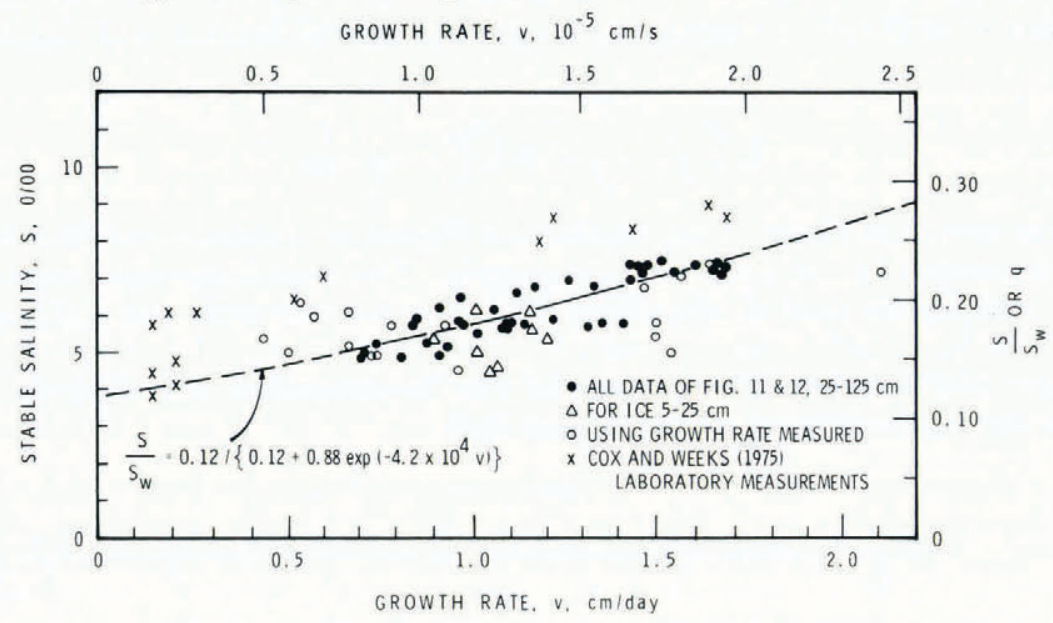

Fig. 13. "Stable" salinity versus growth rate.

The accuracy of the determined growth rate from the observed growth history is questionable primarily because of the large scatter involved in the measurements of ice thickness in comparison with the growth of ice in between measurements. Nonetheless, the observed growth rate is also plotted in Figure 13 for comparison.

The only other available data on this subject, in the present range of growth rates, are the laboratory observations of Cox and Weeks (1975) on $\mathrm{NaCl}$ ice. Their results compare reasonably well with the present observations (Fig. 13) in spite of large differences in the laboratory and natural conditions.

\section{io. Conalusion}

It is shown that a simple theoretical (numerical) prediction of temperature gradient, growth rate, and thickness can be made reasonably well for first-year sea ice in the High Arctic. This is possible only if sufficient data on snow depth and snow density and a record of daily air temperatures are available. Measurements of the vertical salinity profile in the ice at regular intervals of time showed that rapid desalination occurs within about a week 
after freezing. Thereafter, it decreased very slowly (about $0.5 \%$ per month) during the rest of the growth season. Thus the salinity could be considered to have attained a quasi-stable value within a few weeks after ice formation. The value of this stable salinity is shown to depend on the growth rate prevailing at the time of formation of the ice at the considered depth. The vertical salinity profile, therefore, is dependent on the growth conditions experienced by the ice sheet and hence on the weather conditions during the entire growth season. The observed dependence of stable salinity on growth rate seems to agree with the available results obtained in the laboratory.

The data used in this report were obtained by Steltner Development and Manufacturing Company Limited under Contract No. OSQ 78-0oI93 with the Polar Continental Shelf Project, Energy, Mines and Resources Canada, under the Directorship of Mr G. Hobson. The authors are indebted to Mr Hobson for allowing them to report on this project and to $\mathrm{Mr} \mathrm{H}$. A. R. Steltner for organizing and managing the field activities at Pond Inlet and compiling the results. Special thanks are due to Mr S. Koonark, Mr M. Komangapik, and $\mathrm{Mr}$ S. Koonoo for their efforts in collecting the scientific data in the harsh climatic conditions of the Arctic and to Ms D. Komangapik, Ms S. Akoomalik, and Ms J. Arnakallak for performing tedious measurements in the laboratory and tabulating the results.

\section{Agknowledgement}

This paper is a contribution from the Division of Building Research, National Research Council of Canada, and is published with the approval of the Director of the Division.

MS. received I 8 February 1980

\section{REFERENCES}

Anderson, D. L. 1960. The physical constants of sea ice. Research, Vol. 13, No. 8, p. 310-18.

Anderson, D. L. 1961. Growth rate of sea ice. Journal of Glaciology, Vol. 3, No. 30, p. I I 70-72. [Letter.]

Bennington, K. O. 1967 . Desalination features in natural sea ice. Fournal of Glaciology, Vol. 6, No. 48, p. 845-57.

Billelo, M. A. 196r. Formation, growth, and decay of sea ice in the Canadian Arctic Archipelago. Arctic, Vol. I4, No. I, p. 2-24.

Burton, J. A., and others. 1953. The distribution of solute in crystals grown from the melt. Pt. I. Theoretical. [By] J. A. Burton, R. C. Prim, and W. P. Slichter. Fournal of Chemical Physics, Vol. 21, No. 11, p. 1987-91.

Carslaw, H. S., and Jaeger, H. C. 1959. Conduction of heat in solids. Second edition. Oxford, Clarendon Press.

Cox, G. F. N., and Weeks, W. F. 1975. Brine drainage and initial salt entrapment in sodium chloride ice. U.S. Cold Regions Research and Engineering Laboratory. Research Report 345.

Fukutomi, T., and others. 1950. Kaihyō no kenkyū (dai 6 pō). Kaihyō no atsusa no zōka ni tsuite [Study of sea ice (6th report). On the increase of the thickness of sea ice]. [By] T. Fukutomi, K. Kusunoki, and T. Tabata. Teion-kagaku: Low Temperature Science, Ser. A, [No.] 3, p. 171-86.

Fukutomi, T., and others. 1951. Kaihyō no kenkyū (dai I I pō). Abashiri, Monbetsu ni okeru engan kaihyō chū no ensoryō ni tsuite [Study of sea ice ( 1 ith report). On chlorinity of the coastal land ice observed at Abashiri and Monbetsu in Hokkaido]. [By] T. Fukutomi, K. Kusunoki, and T. Tabata. Teion-kagaku: Low Temperature Science, Ser. A, [No.] 6, p. 71-83.

Kolesnikov, A. G. 1958. On the growth rate of sea ice. (In Arctic sea ice. Washington, D.C., p. 157-6r. ([U.S.] National Academy of Sciences-National Research Council Publication 598.))

Malmgren, F. 1927. On the properties of sea ice. The Norwegian North Polar Expedition with the "Maud", 1918-1925. Scientific Results, Vol. I, No. 5 .

Mellor, M. 1977. Engineering properties of snow. Journal of Glaciology, Vol. 19, No. 81, p. 15-66.

Ono, N. I968. Kaihyō no netsuteki seishitsu no kenkyū. IV. Kaihyō no netsuteki na shoteisū [Thermal properties of sea ice. IV. Thermal constants of sea ice]. Teion-kagaku: Low Temperature Science, Ser. A, [No.] 26, p. 329-49.

Pitman, D., and Zuckerman, B. 1967 . Effective thermal conductivity of snow at $-88^{\circ},-27^{\circ}$, and $-5^{\circ} \mathrm{C}$. Journal of Applied Physics, Vol. 38, No. 6, p. 2698-99.

Schwerdtfeger, P. r 963 . The thermal properties of sea ice. Journal of Glaciology, Vol. 4, No. 36, p. 789-8o7.

Simpson, L. S. 1958. Estimation of sea ice formation and growth. (In Arctic sea ice. Washington, D.C., p. $162-68$. ([U.S.] National Academy of Sciences-National Research Council Publication 598.))

Tabata, T. 1958. On the formation and growth of sea ice especially on the Okhotsk sea. (In Arctic sea ice. Washington, D.C., p. 169-8o. ([U.S.] National Academy of Sciences-National Research Council Publication 598.)) 
Weeks, W. F., and Assur, A. 1963. Structural control of the vertical variation of the strength of sea and salt ice. (In Kingery, W. D., ed. Ice and snow; properties, processes, and applications: proceedings of a conference held at the Massachusetts Institute of Technology, February $12-16$, 1962. Cambridge, Mass., M.I.T. Press, p. 258-76.)

Weeks, W. F., and Lee, O. S. 1958. Observations on the physical properties of sea ice at Hopedale, Labrador. Arctic, Vol. I I, No. 3, p. 134-55.

Weeks, W. F., and Lofgren, G. 1967 . The effective solute distribution coefficient during the freezing of $\mathrm{NaCl}$ solutions. (In Oura, H., ed. Physics of snow and ice: international conference on low temperature science. ... 1966. ... Proceedings, Vol. 1, Pt. 1. [Sapporo], Institute of Low Temperature Science, Hokkaido University, p. 579-97.)

Williams, G. P., and Gold, L. W. 1958. Snow density and climate. Transactions of the Engineering Institute of Canada, Vol. 2, No. 2, p. $9^{1-94}$.

Zubov, N. N. 1938. O predel'noy tolshchine morskikh mnogoletnikh l'dov [The maximum thickness of perennial sea ice]. Meteorologiya i Gidrologiya, 1938, [No.] 4, p. 123-31.

Zubov, N. N. 1945. 'L'dy Arktiki [Arctic ice]. Moscow, Izdatel'stvo Glavsevmorputi. 